\title{
Ensino de Português Brasileiro na Escola Indígena por Professores não- indígenas: uma questão de interculturalidade, de pragmática
}

Teaching of Brazilian Portuguese on indigenous school by non indigenous teacher a question of interculturality, a question of Pragmatics

Antonio Almir Silva Gomes ${ }^{1}$

Universidade Federal do Amapá

Resumo: As populações indígenas brasileiras têm assumido cada vez mais o protagonismo de suas histórias também relacionadas à Educação Escolar Indígena (EEI), inclusive no que se refere à presença em seu interior do professor indígena. Em relação ao ensino de Português Brasileiro (como disciplina), contudo, embora nos ressintamos da ausência de dados oficiais robustos, sabemos da presença em número considerável de professores não-indígenas executando essa disciplina. O presente artigo voltase para essa realidade ao discutir o perfil docente deste professor. Argumentamos em favor de que o ato de ensinar Português Brasileiro na escola indígena pelo professor não-indígena implica uma série de ações que o antecedem. $O$ argumento em questão é sustentado ao longo do artigo por discussões advindas da interculturalidade e da pragmática. Como resultado, pretende-se a um professor ciente de que sua prática docente envolve muito além dos conteúdos.

Palavras-chave: Ensino; Português Brasileiro; Professor; Interculturalidade; Pragmática.

Abstract: The Brazilian indigenous population has assumed the role of their stories, on the last decades, included the Indigenous School Education system (ISE). This fact has impact on the presence of the indigenous teacher inside of the same system. With regard to the teaching of Brazilian Portuguese as a discipline, although we are resentful of the lack of robust official data, we know based on our own experiences, of the presence of non-indigenous teachers in a considerable number executing this discipline. This paper focuses on this reality and then aims discussing the teaching profile of the BP teacher. Throughout the paper, we argue that the actions related to teach BP by non-indigenous in the indigenous school implies a series of actions that precede it itself. The argument in question is supported by discussions arising from the Interculturality and Pragmatics. As a result, we expect a teacher conscious that the act of teaching (and learning) BP is constituted by much more than a set of content.

Keywords: Teaching; Brazilian Portuguese; Interculturality; Pragmatics.

\section{Introdução}

O presente artigo percorre um caminho assentado na presença do Português Brasileiro como disciplina na escola indígena brasileira e assume a máxima seguinte: aquela protege esta, dito de outra forma, o Português Brasileiro (PB), por seu "status" de língua dominante no contexto nacional, ao adentrar a escola indígena, reconhece e promove a valorização da língua indígena (LI) local; assim o faz entendendo seu lugar e papel no seio da mesma escola. Para os propósitos deste artigo,

\footnotetext{
${ }^{1}$ Esse artigo foi construído no contexto de pesquisas que tenho realizado em virtude do Projeto "Processos Linguísticos de Ensino e de Aprendizagem em Contextos de Educação Escolar Intercultural Indígena" financiado pelo CNPq (Universal, 2016, Processo n. 424117/2016-9), a quem agradeço. Agradeço, igualmente, aos professores de Português Brasileiro que atuam em escolas indígenas do Estado do Amapá e do norte do Pará por compartilharem comigo tantas ricas experiências.
} 
consideramos (i) cenários de populações indígenas que têm o PB como língua não materna² sabendo que há inúmeras populações indígenas que a têm como língua materna - (ii) PB língua majoritária e a LI língua minoritária. Esses termos são adotados aqui exclusivamente no sentido de que majoritária porque predominante na escola e minoritária porque tem destinados espaços específicos. Nesse contexto, o presente artigo volta-se a escolas indígenas que ofertam Ensino Fundamental II e o Ensino Médio; isto porque há muitos casos de escolas indígenas em que o Ensino Fundamental I é realizado majoritariamente utilizando-se da LI.

A dicotomia língua majoritária e língua minoritária adotada ao longo do artigo corresponde a pensar um cenário em que a primeira exerce forte influência sobre a segunda, já que, para fora da comunidade indígena, é pelo PB que a escola interagirá. Este é um dos fatores que têm justificado a presença desta língua como disciplina na programação da Educação Escolar Indígena. As populações indígenas brasileiras reconhecem a importância e/ou a necessidade dessa disciplina em suas escolas. A este respeito, por exemplo, Tavares (2016, p. 368), ao se referir a populações Guarani Kaiowá e Guarani Ñandeva que vivem no Estado do Mato Grosso do Sul, afirma que para estas populações, falantes de suas línguas maternas, o PB é importante e tem como "[...] motivação principal de seu ensino/aprendizado a necessidade de contato com a população não indígena". Camargos (2012), utilizando-se de um conjunto de relatos adquiridos "durante aulas no curso de Licenciatura Básica Intercultural da Universidade Federal de Rondônia, Campus de Ji-Paraná", aponta para a importância do PB caracterizada pelo "[...] papel central nas comunidades e escolas indígenas, pois se tornou o meio eficaz para comunicação com a sociedade envolvente [...]" (CAMARGOS 2012, p. 03-04). O Instituto Socioambiental, por sua vez, tomando como base o Referencial Curricular Nacional para as Escolas Indígenas, considera o aprendizado e uso do PB “[...] um dos meios de que as sociedades indígenas dispõem para interpretar e compreender as bases legais que orientam a vida no país, sobretudo, aquelas que dizem respeito aos direitos dos povos indígenas".

A presença do PB na escola implica a figura do professor que ensinará essa língua, o professor de PB. Pelo conjunto de justificativas apresentadas, torna-se inquestionável a importância desse professor que, com sua ação de ensinar, constitui o escopo deste artigo. Quando se pensa o referido professor no contexto das escolas indígenas, como que numa mimese da Educação Escolar não Indígena (EEnl), assim se faz atrelando-o ao conceito da qualidade de sua formação acadêmica. Imagina-se o bom professor como aquele que construiu uma formação acadêmica sólida ou mesmo que já possui histórico de relações com esta ou aquela população indígena, ou que participa ativamente das atividades regulares da comunidade. Este professor, em sua maioria, conforme mencionamos, ainda é um indivíduo não pertencente à comunidade indígena atendida pela escola.

As ações que este professor desenvolve em suas aulas, contudo, não têm entrado no bojo daquilo que o qualificam nacionalmente, da mesma forma, a maneira como se dá sua preparação prévia como não pertencente àquele povo (indígena) para o ato de ensinar língua igualmente não

\footnotetext{
2 Utilizamos o termo língua não materna ao longo deste artigo a fim de não adentrarmos em discussões teóricas (necessárias em contextos que ultrapassam o escopo do presente artigo) que nos levariam à apropriação e até mesmo à problematização de termos como segunda língua, língua adicional, língua de herança etc. Como nosso objetivo se volta para contextos de populações em que a língua materna é a indígena, consideramos esse artigo instrumento não apropriado para as discussões teóricas em questão, por isso, PB sob o rótulo adotado.
} 
pertencente à comunidade como língua materna. É este cenário que nos interessa neste artigo, logo, seu escopo recai sobre o perfil do professor de PB que atua(rá) na sala de aula da escola indígena brasileira. Nós consideramos que este professor, ao ensinar PB, deve colocar-se como defensor da LI, reiterando sempre, o tempo, o papel e o lugar de cada uma das línguas. Essa dinâmica em que a aula de PB atua no sentido de proteger a aula de LI demandará do professor de PB as seguintes ações: (i) considerar a influência de uma língua sobre a outra, no caso, LI sobre PB; (ii) entender o comportamento linguístico e social do aluno. O comportamento linguístico o fará entender como seu aluno vai se comunicar, utilizando-se de quais estratégias linguísticas, em quais contextos. Por outro lado, o comportamento social o fará entender quem é esse aluno, se é uma mulher ou um homem, se é um idoso, se pertence a este ou àquele clã etc.; consequentemente, como lidará com cada uma das variáveis em questão.

A seguir, utilizando-nos de duas seções, discorremos sobre (i) e (ii). Em Algumas notas sobre o professor e seu objeto, o PB (2), discorremos sobre a necessidade de que o professor conheça seu público alvo em suas especificidades e direcione seu planejamento levando em consideração esse conhecimento (2.1). Na sequência, apontamos para especificidades do PB produzido por distintas populações indígenas brasileiras (2.2). O tratamento dessas especificidades na seção 3, intitulada Ensino de PB, interculturalidade e Pragmática, deve-se dar utilizando-se de pressupostos interculturais (3.1) e pragmáticos (3.2).

\section{Algumas notas sobre o professor e seu objeto, o PB}

A presente seção ocupa-se com o professor de PB e seu objeto. Assim o faz com o objetivo de trilhar caminho que considere a preparação prévia deste para o ensino do $\mathrm{PB}$, sendo este professor não membro da comunidade indígena atendida e que, por isso, não compartilha conhecimentos tácitos da referida comunidade. No caminho trilhado, a concepção de que ensinar - consequentemente aprender - PB implica muito mais que o "repasse" de conteúdo programático recebido de uma autoridade municipal ou estadual de educação.

\subsection{O professor}

O professor de PB precisa ter em mente o significado desta língua na comunidade, logo, compreende que diferentes realidades demandam diferentes comportamentos. A seu lado, atenção e busca de respostas permanentes a questões tais como: Para quê querem esta língua? A comunidade tem consciência disso, ou o PB está na escola porque estão também as demais disciplinas? A consciência dessa realidade é importante ao professor porque o guiará em suas ações. Ele se perguntará continuadamente acerca de qual PB levará à escola. O PB do conteúdo programático recebido pela secretaria estadual ou municipal de educação? $O$ PB das metalinguagens? O PB formal? Para qual fim o PB na escola? Para comunicar (oralmente) com os vizinhos da região? Para fazerem negócios com esses vizinhos? Para atender às suas necessidades locais? Para o contato com o mundo escrito em PB que lhes chega pelo celular, pela televisão?

Com estas perguntas em mente - que nos permitem pensar, inclusive, sobre a possibilidade de que o ensino de PB deva ser moldado para o caso das populações indígenas brasileiras que a têm 
como língua não materna com base em metodologias do ensino de línguas para fins específicos, algo como Ensino de Português para Fins Específicos na Escola Indígena Brasileira (EPOFEIB) - o professor entende que no contexto do ensino de PB na escola indígena não basta pensar o que ensinar; é necessário perguntar-se reiteradamente como e a quem ensinar. Antes de pensar o que ensinar, portanto, o professor de PB precisa pensar em como interagirá e atingirá seu público alvo eficazmente. Essa relação entre o quê, como e a quem, já tendo em mente, também, para quê ensinar, presume planejamento docente rigoroso cuja essência seja a atenção ao público alvo. Sem a companhia das perguntas e planejamento mencionados, adentra ao espaço da escola indígena um professor que entende que seu trabalho consiste unicamente em ensinar PB a uma população indígena. Para o contexto deste artigo, não é deste professor de PB que a escola indígena precisa. Ao contrário, consideramos que a escola indígena precisa de um professor consciente do fato de que uma série de questões se relaciona com sua prática e objeto docente.

Igualmente importante ao professor de PB é a compreensão de que o aprendizado desta língua deve ser usado como pretexto para a compreensão do valor da LI. O professor deve ser um incentivador da não polarização PB versus LI, como se fossem aprendizados excludentes. Este professor sabe que o aprendizado de uma língua não implica perda ou estigmatização de outra e, mais importante, que seu aluno convive com múltiplas línguas cotidianamente, pré-disposto, portanto, a aprender novas línguas. O professor tem ciência de que cada uma das línguas é possuidora de lugares, funções e valores próprios. Da mesma forma, o professor sabe que a LI exercerá influência sobre o PB (2.2) e que esse jogo linguístico terá efeito sobre o aprendizado do $\mathrm{PB}$, ao mesmo tempo em que revela fato natural das línguas, a variação linguística causada por contatos. Trata-se de um professor preparado para o trabalho com línguas; consciente de que língua (e seu ensino e aprendizado) é influenciada por fatores sociais, culturais e contextuais (3), logo, reflete questões culturais que precisam ser observadas. Assim sendo, como reiteramos ao longo do artigo, o professor entende que sua presença na sala de aula, bem como suas ações pedagógicas, não implicam apenas em boas práticas relacionadas ao conteúdo em si, implicam também estar atento a questões que antecedem sua entrada na sala de aula e, da mesma forma, sua permanência. O professor está inserido em um contexto cultural que demanda comportamentos sociais e linguísticos próprios; entendê-lo constitui-se necessidade primordial ao êxito de práticas de ensinar e de aprender PB.

\subsection{O objeto, $P B$}

Em texto de 2010, Maher, ao apontar para "[...] uma situação de assimetria linguística com forte tendência favorável à expansão do português e ao enfraquecimento das línguas indígenas locais" (MAHER, 2010, p. 35) inerente às populações indígenas do Estado do Acre, relata a experiência de "[...] um grupo de 40 professores indígenas locais, de 07 diferentes etnias (Kaxinawa/Huni Kui, Yawanawa, Shãwãdawa, Katukina, Jaminawa, Asheninka e Manchineri)" que "[...] vêm, desde o início da década de 90, demonstrando uma forte mobilização social e política em favor do fortalecimento das línguas de seus ancestrais" (MAHER, 2010, p. 36). Segundo a autora, as ações do grupo de professores visam a "[...] garantir a continuidade da existência das línguas indígenas acreanas [...]" (MAHER, 2010, p. 36). As discussões empreendidas com os professores que 
compunham o grupo mencionado os conduziram a concepção de que "[...] é através da promoção de um ensino eficiente da língua nacional do país nas escolas das aldeias que esses professores esperam convencer as famílias indígenas a investirem na transmissão de suas línguas tradicionais a seus filhos" (MAHER, 2010, p. 41). Na esteira das discussões, segundo Maher (op. cit.), entre os professores, delineia-se perspectiva de que "[...] a língua portuguesa passa a ser vista, não apenas como a grande vilã, mas também como uma possível aliada no projeto de fortalecimento das línguas indígenas locais" (MAHER, 2010, p. 41). Junto à necessidade de fortalecimento das línguas indígenas locais, portanto, os professores discutiram e reconheceram a importância do PB. É o que vemos expresso, também, nos excetos a seguir apresentados por Maher (2010, p. 41), nos quais mantivemos os códigos e negritos utilizados pela autora:

PI1: Num tem jeito, mesmo, porque a gente precisa da língua portuguesa, como disse a
Fátima, né? A gente precisa negociar, comprar as coisas, falar com o prefeito, com o pessoal
da Secretaria [de Educação]... Então é por isso que muitos pais querem ir levando as duas
línguas juntas, né? Um pouco da língua14, mas também um pouco do português...
P: E o português vai aprender como?
PI2: Na escola, professora, na escola... a língua aprende com a mãe e com o pai e o
português aprende na escola, eu acho assim...

PI4: A gente tem que melhorar mais o ensino do português na escola... eu acho assim...

PI3: É, tem que melhorar mais, mas TEM que convencer também... porque o pai tem que acreditar também. $\mathbf{O}$ próprio professor tem que acreditar [no ensino de português na escola] porque senão ele mesmo num vai/ ele VAI ensinar [a língua portuguesa] pro filho dele já logo que o filho já nasce...

Do ponto de vista do PB escrito por populações indígenas brasileiras, pesquisadores têm descrito diferentes aspectos. Lima e Silva (2012) aponta para o caso Kaingang, em que, segundo a autora, é "[...] comum ausência de concordância verbal e nominal” (LIMA e SILVA, 2012, p. 5). Como exemplo, a autora (op cit.), menciona casos como: "Por que agente Ama você agente te tratam com carinho". Na sequência, Lima e Silva (2012, p. 6) aponta para D’Angelis (2004), segundo quem:

“Na língua Kaingang não existe concordância de número entre o verbo e seus argumentos. A língua Kaingang exprime ação plural, múltipla ou repetitiva no verbo, seja por reduplicação, seja por alternância lexical. A expressão da ação plural, múltipla ou repetitiva no verbo pode tornar redundante e, portanto, levar a omitir a marca plural tanto no SN Sujeito como no Objeto." (D’ANGELIS, 2004, p.75, apud LIMA e SILVA, 2012, p. 6).

Brandão (2017, p. 169), ao relatar sua experiência de "[...] pesquisa que teve como finalidade diagnosticar, compreender e refletir sobre o ensino de língua portuguesa no contexto bilíngue de uma escola indígena de uma reserva indígena da região de Dourados/MS", apresenta os excetos a seguir - nos quais mantivemos os negritos da autora - escritos por alunos do 2o ano do Ensino Fundamental.

Exceto I: Branca de neve ele en cotro corruga ele levou na casa dele comeu de pois domi branca de neve marava com pai dele pois pai dele morreu de pois ele mora na casa de madrata. 
Exceto II: Era uma vez um minina que tão bonito atem ela entrou um pricipi ficarum felize e cicazaram

Exceto III: Era um branca de neve que era mais bonita de todos gostava dele é um dia a padrasta ficou invejozo é falou para o espelho queí é mais bela de todos é você dis o espelho ea padrasta dela comesou a pular e falou di novo [sic] (RAMOS, 2002, p. 40 (grifos da autora).

Em excetos de textos em PB escritos no ano de 2019 por alunos que frequentam o segundo ciclo do Ensino Fundamental em escolas indígenas do estado do Amapá, temos exemplos como (I) e (II) abaixo produzidos por dois alunos distintos:

Exceto I: "O papagaio é um ave de cor verde e de pena macio, ele tem bico duro. Ele vive no mato, o papagaio dormir mas alto em cima da galho da árvores. Ele voa procura a frutas. $\mathrm{O}$ papagaio comer, bacaba, cupui.."

Exceto II: “A cutia é um animal pequeno que vive no qualquer lugar ela viver na terra. Ela é cor amarela tem o pelo macio. A cutia gosta de dormir buraco da arvore caída ela gostar de andar de manhã..."

Nos excetos acima representativos de diferentes povos indígenas brasileiros, observamos (i) ausência de concordância em distintos sintagmas, como em [o papagaio é um $\varnothing$ ave], [de pena maci[o]], [procura aø frutas], além daqueles destacados em negrito; (ii) ausência de determinantes no sintagma, como em [ele voa $\varnothing$ procura a frutas], [ela é $\varnothing$ cor amarela], [de dormir $\varnothing$ buraco da arvore]; (iii) ortografias próximas da oralidade, como em $\mathrm{m}$ [i]nina, ficar[u]m, [cicazaram], come[s]ou ou não padrão, como em [pricipi], invejo[z]o, di[s].

Características como essas foram apontadas por Gomes (2012) como presentes no PB em uso por professores indígenas do Estado do Amapá. A observância de (i) demonstra semelhanças entre o PB escrito por usuários indígenas do estado do Amapá e pelos demais usuários mencionados, o que aponta para recorrência de certos padrões de uso do $\mathrm{PB}^{3}$. Padrões característicos de alunos em contexto de aprendizado de uma língua não materna não são exclusivos dos povos aqui mencionados, ao contrário, refletem característica inerente ao ato de aprendê-la. Roever (2011, p. 564), por exemplo, indica que "pesquisas em SLA têm mostrado que certos recursos de L2 são difíceis de serem adquiridos sem instrução ao aluno, por exemplo, colocação de advérbios (White, 1991) ou interrogativos para alunos franceses de inglês (White et al., 1991)"4. O efeito dessa dificuldade certamente será a colocação de advérbios ou o uso de interrogativos, considerando-se o "padrão da língua", em lugares não esperados pela forma padrão, logo, característica de aprendizado semelhante ao que vimos nos exemplos (i), (ii) e (iii) apresentados.

Ainda considerando-se as características dos exemplos (i), (ii) e (iii), temos que o PB escrito por populações indígenas levanta a questão da relação que se estabelece entre uma língua materna

\footnotetext{
${ }^{3}$ A observância de (i) nos conduz, também, à compreensão de questões relacionadas à concordância no sintagma são atestadas entre usuários que têm o PB como língua materna; destaque-se a marcação de plural produtiva no determinante e ausente no resto do sintagma, como em $a[s]$ flor $[\varnothing], o[s]$ menino[ø] etc.

${ }^{4}$ Tradução livre de: "SLA research has shown that certain L2 features are difficult for learners to acquire without instruction, e. g., adverb placement (White, 1991) or interrogatives for L1 French-speaking learners of English (White et al., 1991)".
} 
e outra(s) língua(s), tema tão discutido no âmbito da Linguística e da Linguística Aplicada (DERAKHSHAN; KARIMI, 2015) ${ }^{5}$. Não é nosso objetivo neste artigo esse tipo de discussão (interessante e necessária), mas discutirmos a reação do professor de PB (a língua não materna) frente às mesmas características, sobretudo, considerando-se que esse professor terá em mãos um conteúdo específico para ensinar e uma modalidade específica de língua a "cobrar" (padrão). Assim sendo, ao considerarmos, como o grupo de professores indígenas do Acre, que "Num tem jeito, mesmo, porque a gente precisa da língua portuguesa" e que a língua (escrita) com a qual o professor se deparara em sua prática cotidiana de sala de aula apresentará características próprias, a questão que se coloca é: como agir na prática cotidiana de sala de aula de modo a identificar as especificidades da relação LI versus PB e, ao mesmo tempo, respeitar, compreender e empoderar o aluno no uso do PB (escrito, se for o caso)? Resposta a essa pergunta, conforme (3) seguinte, perpassa pela compreensão intercultural do ato de ensinar PB (3.1); consequentemente, pela compreensão, do professor, da relação que a língua estabelece com fatores pragmáticos (3.2).

\title{
3. Ensino de PB, interculturalidade e Pragmática
}

Larsen-Freeman e Anderson (2016, p. ix) consideram que:

\begin{abstract}
“O trabalho de ensinar é simultaneamente mental e social. É também físico, emocional, prático, comportamental, político, experiencial, histórico, cultural, espiritual e pessoal. Em síntese, ensinar é bastante complexo, influenciado não apenas por essas 12 dimensões e talvez outras, mas também requerendo orquestração em apoio ao aprendizado dos alunos. Quando o ensino de língua é o foco, a complexidade é ainda maior, já que influenciada pela compreensão do professor acerca da natureza da linguagem, pelo processo de ensinar e de aprender em geral, bem como por seu conhecimento das características socioculturais particulares em que o ensino e o aprendizado se dão (ADAMSON 2004)”6.
\end{abstract}

Larsen-Freeman e Anderson (2016) ilustram a complexidade envolvendo o ato de ensinar língua, nos conduzem, sobretudo, por um caminho no qual fica evidente a necessidade de considerarmos fatores externos à própria língua. Para o contexto da sala de aula de PB na escola indígena, consideramos que esses fatores perpassam pelo comportamento intercultural e pela compreensão pragmática, pelo professor, do contexto no qual está inserido.

\subsection{Interculturalidade e ensino de línguas}

Interculturalidade é uma palavra cuja definição mostra-se complexa. Nos termos de Zaráte Pérez (2014, p. 96), "não há um conceito específico para ela, a tal ponto de tornar-se abstrata sua

\footnotetext{
${ }^{5}$ A relação / presença de uma língua (materna) sobre outra língua (não materna) tem gerado discussões, por exemplo, no âmbito da Linguística Cognitiva, a exemplo de Ibáñez e Llach (IBÁÑEZ, F. J. R. de M.; LLACH, M. del P. A. Cognitive Pedagogical Grammar and meaning construction in L2. In: de KNOP, S.; GUILQUIN, G. (Eds.). Applied Construction Grammar: application of Cognitive Linguistics. Mouton de Gruyter, 2016, p. 151-183).

${ }^{6}$ Tradução livre de: "The work of teaching is simultaneously mental and social. It is also physical, emotional, practical, behavioral, political, experiential, historical, cultural, spiritual and personal. In short, teaching is very complex, influenced not only by these 12 dimensions and perhaps others, but also requiring their contingent orchestration in support of students' learning. When language teaching in particular is in focus, the complexity is even greater, shaped by teachers' views of the nature of language, of language teaching and learning in general, and by their knowledge of the particular sociocultural setting in which the teaching and learning take place (Adamson 2004)."
} 
definição [...]". Assim sendo, o autor apresenta algumas concepções atreladas à interculturalidade, dentre as quais aquela que a considera "um diálogo entre culturas", a "ausência de hierarquias entre as culturas ou povos, sendo as culturas abertas e suscetíveis de mesclarem-se", a "tolerância e respeito entre as culturas". Segundo o autor, "interculturalidade, mas que um conceito, é um projeto político (ZARATE PÉREZ, 2014, p. 97)”.

Para além das discussões conceituais e/ou teóricas, Interculturalidade tem sido adotada no contexto do ensino de línguas. Nesse caso, a relação se volta para a presença de aspectos da cultura do outro no ato de ensinar e de aprender língua. De acordo com Liddicoat (2004), "uma abordagem intercultural de ensinar e de aprender uma língua envolve quatro atividades principais relacionadas à cultura", quais sejam: aquisição sobre cultura, comparação entre culturas, exploração cultural e encontrar um "terceiro lugar" entre culturas. Nesse conjunto de atividades em que se relacionam a percepção, a comparação, a reflexão e a interação, segundo Liddicoat (2011, p. 841) "o nível mais básico de operações que os estudantes podem desempenhar em suas experiências de língua e cultura é a comparação através da qual identificam semelhanças e diferenças" ${ }^{\prime 7}$. Nesse conjunto de atividades ainda, segundo Liddicoat (2011, p. 843), devem constar atividades que permitam:

1. Construir a cultura de base do aluno e a cultura-alvo como representações da vida humana igualmente válidas.

2. Visualizar instâncias de uso da língua como experiências e oportunidades para o aprendizado cultural.

3. Focar em capacidades necessárias para a aprendizagem contínua de culturas através de experiências com a língua.

4. Encorajar a inclusão de múltiplas perspectivas.

Perspectivas interculturais no ensino de línguas são temas interessantes e necessários de serem pensados para o contexto do ensino de PB nas escolas indígenas, já que permitem o conjunto de atividades e comportamentos mencionados para as quais se tem como fim, dentre tantos outros, o tratamento igualitário das diferentes línguas envolvidas. Para o contexto do presente artigo, contudo, o caminho intercultural a ser adotado deve ser invertido no sentido de que a preocupação primeira não recaia sobre a discussão, a interação pelo aluno da cultura "carregada" pelo PB, mas o próprio professor de $\mathrm{PB}$, sobre o qual recaia a discussão, a interação com a cultura "carregada" pela LI. Este caminho é necessário uma vez que o professor precisa entender-se inserido em um contexto intercultural, não apenas ver seu aluno como tal. O efeito dessa compreensão incide sobre suas ações metodológicas, que devem partir da busca da compreensão do outro (o aluno) e de sua cultura, não o inverso. Ao agir desta forma, o professor olhará também para a língua (do outro) buscando entendê-la em seus aspectos propriamente linguísticos, mas também pragmáticos.

A interculturalidade aqui considerada permitirá ao professor entender que a diferença é natural, mas também que muito do que encontrará no aprendizado do PB é reflexo linguístico da língua materna do aluno. Tais entendimentos são importantes ao conduzir o professor ao respeito a seu aluno entendendo que não é porque este produz "erro de gramática" (2.2) ou demonstra não aprendizado nos moldes daquilo que aquele espera que ele será reprovado. A atenção prévia pelo

\footnotetext{
${ }^{7}$ Tradução livre de: "The most basic level of operations that students can perform on their experiences of language and culture is comparison in which students identify similarities and differences. The process of comparison is multilayered."
} 
professor ao contexto intercultural do aluno o permitirá entender as especificidades deste a partir daquilo que ele é como membro de uma sociedade indígena que, inclusive, convive em um contexto multilíngue, como ocorre no caso do Parque Nacional do Tumucumaque (GOMES, BARBOSA, FERREIRA, 2020). A centralidade do aluno no contexto de ensino e de aprendizado se molda a partir do momento em que o professor se molda em suas atitudes, crenças, comportamentos, conhecimentos, etc. No modelo intercultural aqui pensado, o professor usa interculturalidade para entender o outro, antes de esperar que o outro o entenda; processo posterior. As atribuições que cumulam na qualidade do professor (Seção 1), desta forma, são expandidas para aquilo que o caracteriza diante do outro, seu aluno, o povo atendido pela escola.

Com esse perfil docente, torna-se mais exequível uma perspectiva de Ensino de Línguas em Contexto Indígena (ELCIND) assentada no diálogo, na ausência de hierarquias, na tolerância e respeito entre as culturas, com efeito na equidade de ciências e de conhecimentos presentes na escola, de modo que o PB, língua majoritária, não se sobreponha à língua minoritária, mas, ao contrário, reconheça seu lugar, seu tempo e seu espaço. Esse cenário reconhece a importância de cada uma das línguas na escola segundo aquilo que a própria comunidade atendida definira.

\subsection{Pragmática}

Roever (2011, p. 560), baseado em Crystal (1977), Mey (2011) e Levinson (1983), considera que:

Pragmática é comumente vista como o estudo da língua em uso (Crystal,1977; Mey, 2001), destacando a incorporação de fatores contextuais no discurso (1983). Esses fatores contextuais podem incluir, por exemplo, a configuração física em que o discurso ocorre, a relação entre os participantes nos termos de Brown e Levinson (1987), fatores de relacionamento (poder relativo, grau de imposição, distanciamento social) e o conhecimento compartilhado dos participantes sobre o tópico discursivo bem como os papeis e normas sociais. (ROEVER, 2011, p. 560) ${ }^{8}$

Nesta definição, são evidenciadas a importância e o papel de fatores externos à língua, encapsulada sob o rótulo discurso. A observação dos participantes em suas mais variadas faces e características torna-se relevante para a construção do discurso; não importa aquele que o produz, mas também aquele com o qual interage, as relações que se estabelecem entre estes e o meio no qual é produzido. Essa compreensão (pragmática) que amplia os atores envolvidos no uso da língua (do discurso) destacando a importância do contexto em que os mesmos se constituem, torna-se relevante na medida em que o escopo das ações de ensinar e de aprender volta-se não apenas ao aluno, mas também ao professor de PB. Chegamos, assim, mais uma vez ao professor, tomado aqui como o ponto inicial do processo.

Ao assumirmos com interculturalidade a necessidade de que este professor construa suas ações de ensinar baseado na compreensão linguístico-cultural que constitui seu aluno, aqui assumimos que este professor precisa entender que todo o processo de ensinar e de aprender,

\footnotetext{
${ }^{8}$ Tradução livre de: "Pragmatics is commonly viewed as the study of language in use (Crystal, 1997; Mey, 2011), topicalizing the incorporation of context factors in discourse (Levinson, 1983). Such context factors can include, for example, the physical setting in which the discourse take place, the relationship between the participants in terms of Brown and Levinson's (1987) relationship factors (relative power, degree of imposition, social distance), and the participants' shared knowledge about the topic of the discourse and social rules and norms."
} 
permeado pela cultura, se refletirá no comportamento e, consequentemente, na própria língua do aluno, tendo o contexto pragmático papel relevante. Logo, não é possível ao professor executar esse processo baseado apenas no conteúdo programático. Ele precisa apropriar-se de fatores pragmáticos, em conformidade com as características apontadas por Roever (2011), decorrentes das relações de poder que se estabelecem na sala, além disso, da constituição e da preservação das faces ao longo de todo o processo, da constituição dos turnos de fala se constroem na língua materna do aluno, bem como de questões etárias, de sexo e de pertencimento social definidas na comunidade e na sala de aula. Vejamos a seguir alguns relatos ilustrativos da necessidade de que o professor atenha-se às questões pragmáticas envolvidas em suas ações de ensinar PB na escola indígena.

Certa vez, em sala de aula de 5o Ano do Ensino Fundamental em uma escola indígena estadual localizada no Parque Nacional do Tumucumaque, o professor de PB elogiou um aluno em meio aos demais por seu bom desempenho em atividade proposta, bem como expôs na sala de aula aos demais alunos a atividade em questão. $O$ aluno que fizera a atividade não retornou à sala de aula na semana seguinte. Ciente da ausência do aluno, o professor resolveu ir à casa dele, a fim de saber o que acontecera, afinal, aquele aluno era "o melhor aluno da turma". Na visita, o professor ficou sabendo que aquele aluno ficara consternado pelos elogios públicos frente aos colegas. Isto porque na sala havia alunos mais velhos que não haviam resolvido a atividade com o mesmo rendimento desejado pelo professor. Configurara-se um cenário em que: como ele já sabia muito, ele não precisava mais voltar para estudar. O professor compreendeu, desta forma que, naquele contexto linguístico e cultural, não poderia elogiar em voz alta um aluno em detrimento dos demais, ao contrário, deveria fazê-lo ao grupo como um todo; quando tivesse que fazer a um aluno em particular, deveria fazê-lo pessoal e discretamente.

Outra vez, em escola indígena estadual do Amapá, o professor se deu conta de que seus alunos, especialmente em atividades de ditado, trocavam fonemas esperados para a escrita em PB; eram regulares trocas envolvendo fones $[\mathrm{p}] \sim[\mathrm{b}],[\mathrm{t}] \sim[\mathrm{d}],[\mathrm{f}] \sim[\mathrm{v}],[\mathrm{l}] \sim[\mathrm{r}]$. O professor insistia na correção baseado na ortografia que esperava dos alunos. Somente com o tempo percebeu que se tratava do fato de que a língua materna do aluno não dispunha de determinados fonemas presentes em PB, logo, os alunos utilizavam-se de estratégias de substituição destes fonemas por fonemas presentes em sua língua. A concepção esdrúxula de "erro" pelo professor tornou-se a compreensão das habilidades linguísticas dos alunos capazes de permitir-lhes utilizar-se de recursos linguísticos dos mais complexos.

Num terceiro exemplo, ocorrido também em escola estadual indígena do Estado do Amapá, com o decorrer das aulas, o professor se deu conta do silêncio contínuo da turma, apesar de suas contínuas investidas pró interação coletiva. Ao compartilhar sua percepção com membros da comunidade, se deu conta de que o comportamento da turma resultara da interação desta com a altura da voz do professor. Para a população atendida, ninguém ensina gritando, falando alto. Geralmente, quem ensina, o faz de perto e não fala alto. Esse aspecto da relação pragmática na sala de aula chama a atenção inclusive para questão de sexo, uma vez que, naquele contexto, mulheres falam ainda mais baixo que os homens. Se o professor for homem, a fala com as mulheres na sala 
precisa recobrir-se de uma série de cuidados. O professor entendeu que ensinar PB falando alto poderia ter efeitos sobre o aprendizado dos alunos.

A um professor desatento a essas questões e voltado apenas a seu programa de ensino a cumprir, o resultado de sua ação de ensinar e, consequentemente, de aprender PB, ficará comprometido. Nos exemplos mencionados, vimos a relação estreita entre língua, cultura e contexto, com efeitos, por exemplo, na maneira como se observa e interage com o outro (1응 exemplo), como se produzem, se manifestam e se intercambiam os fonemas das línguas (2o exemplo), como lidar com a altura da voz (3o exemplo). Os efeitos deste último exemplo impactam as aulas de leitura. Para algumas comunidades indígenas do norte do Estado do Pará, segundo comunicação pessoal de professor de PB, leituras coletivas podem sofrer abalos sistemáticos de modo que em muitos casos a leitura deve ocorrer do aluno para o professor, não do aluno para a turma; até que ele se sinta confortável e deseje fazer isso. Nesses casos, o mais indicado é escutar a leitura perto do aluno. Na contramão dessa característica, imaginemos o efeito de ensinar e de aprender causados por um professor que chegue à escola daqueles povos agindo como se age na escola não indígena em que uma boa leitura implica volume de voz, contato visual com os participantes, interação com a plateia independentemente de qualquer aspecto de sexo, idade, pertencimento social, etc.

Nesse jogo pragmático, como dissemos, envolvem-se relações de poder, de constituição e preservação das faces, de organização de turnos conversacionais, de relações socais e etárias etc. 0 professor atento ao referido jogo terá melhores condições de entender as especificidades não apenas no que concerne à língua que o aluno usa (Seção 2), mas ao próprio aluno, potencializandoIhe seu aprendizado (de mais uma língua, já que multilíngue). Tudo isso, para o referido professor, trata-se de um aspecto riquíssimo da diversidade humana, jamais de um problema a ser sanado em sua aula tomando a tríade certo / errado / conteúdo.

\section{Considerações Finais}

O presente artigo voltou-se ao professor não indígena que atua em escolas indígenas de Educação Básica brasileiras. Nesse cenário, consideramos que a esse professor recai uma série de ações que precedem sua entrada e se mantêm quando de sua estadia em sala de aula. Isto porque a língua, seu objeto de trabalho, para o contexto em questão, é vista para além de uma estrutura, estando atrelada a fatores externos; o êxito do ensino fortemente influenciado à presença destes fatores. Interculturalidade foi tratada como compreensão que permite o agir docente baseado no conhecimento da cultura do outro (o aluno). Pragmática foi tratada como compreensão que permite o agir docente baseado na percepção dos aspectos culturais presentes na própria língua (que o aluno apresentará), tendo o contexto como mediador dessa presença. No todo, o artigo vislumbrou uma perspectiva em que o ato de ensinar PB inicia-se muito antes da presença do professor na sala de aula, quando este procura saber o que, para que $(\mathrm{m})$ ensinar e como? Interculturalidade e Pragmática foram pensados, portanto, como temas necessários ao professor, que o permitirão compreender que a presença do PB atua como promovedor da própria LI; que cada língua tem suas particularidades, ao mesmo tempo em que reconhece que o aprendizado de uma não ignora a outra, tendo como resultado a presença de uma sobre a outra. O professor atua como agente de 
promoção linguística em sua aula, seja de PB, seja de LI. Os efeitos positivos dessa atuação se refletirão no uso do PB pelos alunos para os fins que eles elegerem como cidadãos conscientes de seu lugar e de seu protagonismo na historia da humanidade.

\section{Referências}

BRANDÃO, M. O. B. Reflexões sobre o ensino de Língua Portuguesa em contexto indígena. Revista Ñaduty, v. 5, n. 7, 2017, p. 160-187. Disponível em: <http://ojs.ufgd.edu.br/index.php/nanduty/ article/view/7801/4236. Acesso em: 10/04/2020>. Acesso em nov. 2019.

CAMARGOS, L. S. Os desafios do ensino de língua portuguesa para indígenas em cursos superiores interculturais. In: MARTINS, M. A. et alii. (Orgs.). Anais da XXIV Jornada do Grupo de Estudos Linguísticos do Nordeste (GELNE). Natal: EDUFRN, 2012, p.1-8.

DERAKHSHAN, A.; KARIMI, E. The Interference of First Language and Second Language Acquisition. Theory and Practice in Language Studies, vol. 5, n. 10, pp. 2112-2117, October 2015 DOI: http://dx.doi.org/10.17507/tpls.0510.19.

GOMES, A. A. S. Português Brasileiro em uso por professores indígenas do estado do Amapá. In: Simpósio Internacional de Ensino de Língua Portuguesa, 2012, Uberlândia. Anais do SIELP. Uberlândia: Editora da Universidade Federal de Uberlândia, v. 2, 2012. p. 1-13.

GOMES, A. A. S.; BARBOSA, J. O.; FERREIRA, I. V. B. Do bilinguismo ao multilinguismo: um caminho para a escola indígena diferenciada. Caderno de Letras da UFPel, v. 36, p. 257-274, 2020.

INSTITUTO SOCIOAMBIENTAL. Escola, escrita e valorização das línguas. Disponível em: <https://pib.socioambiental.org/pt/Escola, escrita e valoriza\%C3\%A7\%C3\%A3o das 1\%C3\%ADng uas>. Acesso em 15 nov. 2019.

LARSEN-FREEMAN, D.; ANDERSON, M. Techniques and principles in language teaching. 3rd. Ed. Oxford University Press, OUP, 2016.

LIDDICOAT, A.J. Language Teaching and Learning from an Intercultural Perspective. In. ELI HINKEL (Ed.). Handbook of Research in Second Language Teaching and Learning. Volume II. Rutledge Editors, 2011, p. 837-855.

LIDDICOAT, A. J. Intercultural language teaching: Principles for practice New Zealand Language Teacher, 2004, p. 17-24. Disponível em: <https://www.researchgate.net/profile/ Anthony Liddicoat/publication/281571069 Intercultural language teaching principles for pract ice/links/5bc7152fa6fdcc03c7899754/Intercultural-language-teaching-principles-for-practice.pdf> Acesso em 15 nov. 2019.

LIMA e SILVA, M. Ensino de português como segunda língua em comunidades indígenas Kaingang RS. Anais do SIELP. Volume 2, Número 1. Uberlândia: EDUFU, 2012, p; 1-14. Disponível em: < http:// www.ileel.ufu.br/anaisdosielp/wp-content/uploads/2014/07/volume 2 artigo 237.pdf>. Acesso 15 nov. 2019. 
MAHER, T. de J. M. Políticas linguísticas e políticas de identidade: currículo e representações de professores indígenas na Amazônia ocidental brasileira. Currículo sem Fronteiras, v. 10, n.1, pp.3348, Jan/Jun 2010. Disponível em: <http://www.curriculosemfronteiras.org/vol10iss1articles/ maher.pdf. Acesso em 05/09/2019>. Acesso em 15 nov. 2019.

ROEVER, C. Teaching and testing Pragmatics. In: LONG, M. H.; DOUGHTY, C. J. (Eds.). The Handbook of Language Teaching. Wiley-Blackwell, 2011, p. 560-577.

TAVARES, M. Línguas indígenas e língua portuguesa em comunidades indígenas do sul de Mato Grosso do Sul. Revista SIGNUM: Estudos Linguísticos, Londrina, v. 19, n. 2, p. 368-390, dez. 2016.

ZARATE PEREZ, A. Interculturalidad y decolonialidad. Tabula Rasa, Bogotá, n. 20, p. 91-107, Jan. 2014 . Available from <http://www.scielo.org.co/scielo.php?script=sci_arttext\&pid=S1794-489201 $4000100005 \&$ Ing=en\&nrm=iso>. Access on 15 nov 2019. 